\title{
Yoga Therapy and Parkinson's Disease Rehabilitation: A Literary Review
}

\author{
Gianluca Ciardi* \\ *Department of Public Health, University of Naples Federico, Italy
}

Submission: May 2, 2017; Published: June 06, 2017

*Corresponding author: Gianluca Ciardi, Department of Public health, University of Naples Federico, Italy, Tel: +390-817-462-796;

Fax: +390-817-463-895; Email: gianluca.ciardi@unina.it

\begin{abstract}
Yoga therapy has acquired a growing interest by western medicine, particularly for the treatment of orthopedic and psychiatric diseases; its role in neurological rehabilitation, however, remains unclear. In this mini review the role of yoga therapy for parkinson's disease has been examined. A systematic search through the main scientific database (Pubmed, Cinhal, Pedro, Cochrane database for Systematic reviews, Trip database) has been conducted to find RCTs about yoga applications in Parkinson patients. We found a total of 4 articles, which have been fully examined. By the analysis of the papers it's possible to say that yoga is a useful tool to treat Parkinson disease, because of its action on motor symptomps, balance, quality of life. The best treatment frequency is twice a week for three months. Future trials are needed to pass all criticalities of research in this particular field.
\end{abstract}

Keywords: Parkinson's disease; Yoga therapy; Systematic review; Ebm

\section{Introduction}

Yoga is defined as a complex group of physical and mental techniques developed in India, based on the joining of the balance between spirit and body. The starting point of yoga philosophy is the assumption that a disease can obstruct personal growth, making the patient's soul unable to search its freedom from suffering [1]; through a series of breathing, relaxing and selfreflecting experience the patient will return again to calm. Inside the main technique we have a lot of yoga paths, such astantra, mantra, kundalini, bhakti, Jnana, karma, raja and many others, each one with its specific treatment. During last years yoga has been addicted to western medicine, and its use has become habitual to treat musculoskeletal disorders in addition to physiotherapy; a growing literature about back pain [2], osteoarthritis [3] support this idea. Less studied, instead, is the effect of yoga therapy on neurological disorders. The aim of this mini-review is to state the point of EBM about yoga treatment for Parkinson disease, searching the best evidence now available.

\section{Search methodology}

The search has been conducted through the main scientific database (Pubmed, Cinhal, Pedro,Cochrane database for Systematic reviews, Trip database) in order to search RCTs or observational studies about yoga treatment for Parkinson's disease. The search has been conducted by April 2017. The keywords used to search are showed in Table 1.

Table 1: Key words used in the literary research.

\begin{tabular}{|c|c|c|}
\hline Key word 1 & Key word 2 & \multirow{2}{*}{ Boolean Operand } \\
\hline \multirow{2}{*}{ Yoga therapy } & Parkinson disease & \multirow{2}{*}{ And/Or } \\
\cline { 2 - 2 } & Neurologicaldisorders & \multirow{2}{*}{ And/Or } \\
\hline \multirow{2}{*}{ Yoga } & Parkinson disease & \multirow{2}{*}{ And } \\
\cline { 2 - 2 } & Neurologicaldisorders & \\
\hline
\end{tabular}

\section{Selection of studies}

Records were primarly selected by title and abstract; a second screening was made by reading full text articles.

\section{Results}

A total of 233 records emerged by literary search; the screening process was reported in Figure 1 . The only RCTs were four [4-7], but 5 precedent reviews, 2 case reports and a protocol paper were also found. The first two RCTs $[4,5]$ were conducted by Ni Mi and his medical equipe; in the first study [4] he showed the benefits of yoga therapy in a 26 patients cohort. Particularly he wrote a treatment program on 12 weeks for the experimental group; patients were treated twice a week in a yoga session, evaluating bardikynesia, motor symptoms of Parkinson disease, 
muscular strength and quality of life (PDQ 39) as outcome measures. Authors reported a better performance of all domains for yoga group.

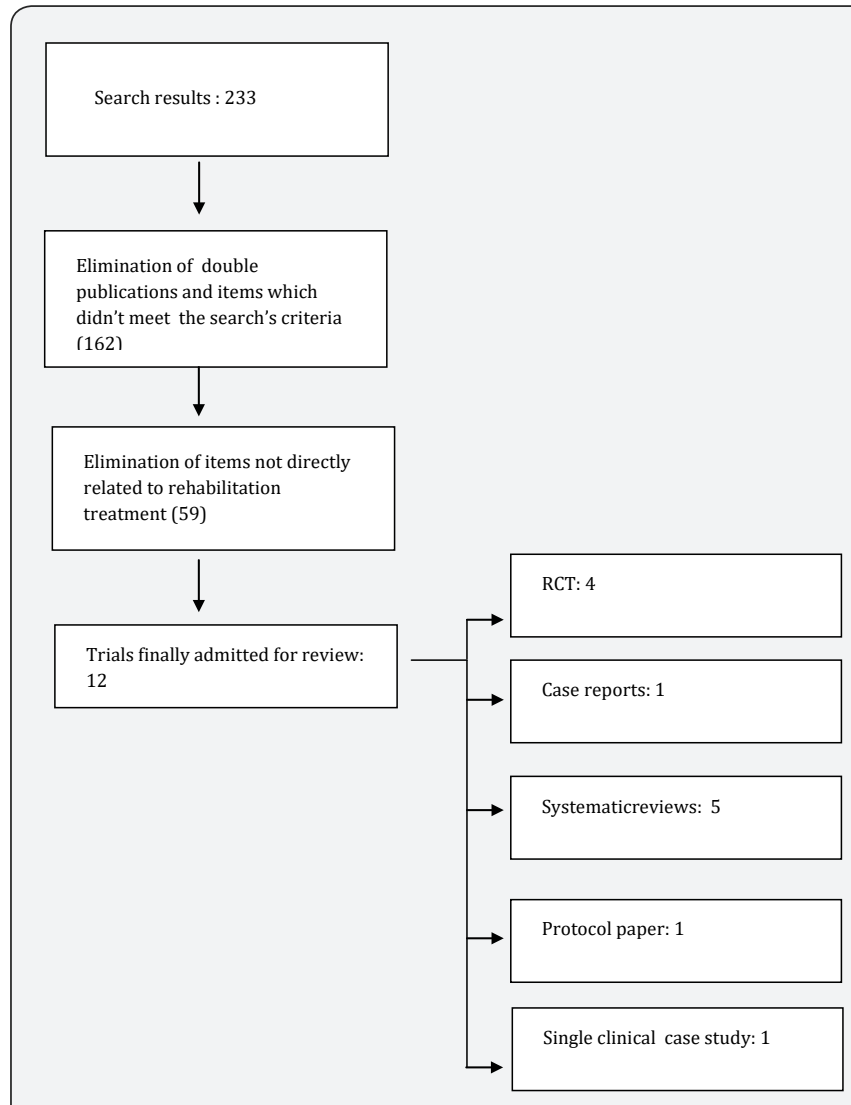

Figure 1: Selection and progressive selection of the literary research results.

In the second experience [5] the same author combined yoga intervention with high speed exercise in a group of 41 patients with Parkinson's disease; timing and outcomes were the same of the precedent article, with the addition of postural and muscular evaluations. The authors described a better performance of experimental group in all domains, suggesting yoga as a useful tool for Parkinson rehabilitation. The study of Sharma et al. [6] examined the effect of a 12 weeks yoga protocol vs control treatment in a group of 13 patients. The yoga session was administred twice a week, and the main out comes were UPDRS and SF-36 for the quality of life. Both these measure were statistically improved in the experimental group. Finally the trial of Calgrove [7] evaluated a protocol of hata yoga intervention in 13 Parkinson patients vs control group; he examined UPDRS ratings, berg scale, Rom analysis, posture and gaitprior, during and after the treatment. According to his analysis, patients in experimental group had an improvement in gait, balance, posture and motor symptoms.

\section{Discussion and Conclusion}

This mini- review has been conduct according to Prisma guidelines. It's possibile to say that yoga is a valid tool to counteract Parkinson's disease; the 4 trials examined reported statistical improvements about motor skills, quality of life and gait for yoga groups. We can also state that a treatment frequency of twice a week is the best to reach the higher result with these patients.This findings agree with the systematic review of Kwok [8], who stated that "mind-body exercises demonstrated immediate moderate to large beneficial effects on motor symptoms, posturalin stability, and functional mobility among individuals with mild to moderate Parkinson disease".The only point that remains unclear is about the specific tecnique to apply: we found a reference to yoga therapy, but only the study of Calgrove specified that the protocol was inspired by hata yoga. Criticalities were found in this research field; inter-operator variability, subjectivity in clinical evaluation, ethic matters for control treatments. These potential sources of bias have to be studied and passed in future and larger trials.

\section{References}

1. Taimini IK (1999) The Science of Yoga: The Yoga-Sutras of Patanjali in Sanskrit. Quest Books New York, NY, USA.

2. Brämberg EB, Bergström G, Jensen I, Hagberg J, Kwak L (2017) Effects of yoga, strength training and advice on back pain: a randomizedcontrolled trial. BMC Musculoskelet Disord 18(1): 132.

3. Kan L, Zhang J, Yang Y, Wang P (2016) The Effects of Yoga on Pain, Mobility, and Quality of Life in Patients with Knee Osteoarthritis: A Systematic Review. Evid Based Complement Alternat Med 2016: 6016532.

4. Ni M, Mooney K, Signorile JF (2016) Controlled pilot study of the effects of power yoga in Parkinson's disease. Complement Ther Med 25: 126-131.

5. Ni M, Signorile JF, Mooney K, Balachandran A, Potiaumpai M, et al. (2016) Comparative Effect of Power Training and High-Speed Yoga on Motor Function in Older Patients With Parkinson Disease. Arch Phys Med Rehabil 97(3): 345-354.

6. Sharma NK, Robbins K, Wagner K, Colgrove YM (2015) A randomized controlled pilot study of the therapeutic effects of yoga in people with Parkinson's disease. Int J Yoga 8(1): 74-79.

7. Colgrove YS, Sharma N, Kluding P, Potter D, Imming K, et al. (2012) Effect of yoga on motor function in people with Parkinson's disease: a randomized, controlled pilot study. J Yog Phys Ther 2(2): 112.

8. Kwok JYY, Chow CK, Lai CHY (2016) Effects of mind-body exercises on the physiological and psychosocial well-being of individuals with Parkinson's disease: a systematic review and meta-analysis. Complement Ther Med Dec 29:121-131. 
This work is licensed under Creative Commons Attribution 4.0 License DOI: 10.19080/JYP.2017.01.555567
Your next submission with Juniper Publishers will reach you the below assets

- Quality Editorial service

- Swift Peer Review

- Reprints availability

- E-prints Service

- Manuscript Podcast for convenient understanding

- Global attainment for your research

- Manuscript accessibility in different formats

( Pdf, E-pub, Full Text, Audio)

- Unceasing customer service

Track the below URL for one-step submission https://juniperpublishers.com/online-submission.php 